\title{
Detrusor Inhibition in Suprasacral Spinal Cord Injuries: Is it Due to Sympathetic Overactivity?
}

\author{
J. F. Mathe, M.D., ${ }^{1}$ J. J. Labat, ${ }^{1}$ J. M. Lanoiselee $^{1}$ and J. M. Buzelin ${ }^{2}$ \\ ${ }^{1}$ Service de Rééducation Fonctionnelle, Hôpital Saint-facques, C. H. U. 44035 \\ Nantes. ${ }^{2}$ Clinique Urologique, C.H.U.-44035, Nantes, France
}

\begin{abstract}
Summary
The authors report five patients with detrusor inactivity in suprasacral spinal cord lesions with perineal spasticity. In all of these cases with cervical or high thoracic lesions treatment with an alpha-blocking drug (Phenoxybenzamine) allowed bladder activity to return. These results suggest that the sacral parasympathetic centre is under the inhibitory influence of the sympathetic nervous system.
\end{abstract}

Key words: Detrusor inactivity; Alpha-blocking agents; Spinal cord lesions; Urodynamics; Urinary bladder neurophysiology.

\section{Introduction}

In suprasacral spinal cord lesions, the bladder usually shows uninhibited detrusor contractions. In some patients, after the disappearance of spinal shock, it was found that the bladder remained areflexic necessitating intermittent catheterisation. To explain such cases, the following hypothesis can be put forward: overdistension of the bladder with hypotonia, lower motor neuron lesions, or reflex inhibition of the detrusor from the external striated sphincter. We hereby report five patients in whom bladder activity reappeared following the administration of Phenoxybenzamine (P.O.B.). These observations suggest the role of a hypothetical detrusor inhibition mediated by the sympathetic system (Labat et al., 1982).

\section{Materials and methods}

Four male patients have been examined two weeks after spinal cord injury and a fifth patient who could walk was investigated 2 years post injury (Fig. 1). The upper level of the neurological lesion was C5, C6, C7, T1 and T4. Three of the patients had a complete lesion and two had an incomplete lesion and could walk. After spinal shock all patients became spastic. Conus reflexes, ankle and knee jerks and abdominal reflexes were present. However, the bladder did not show 


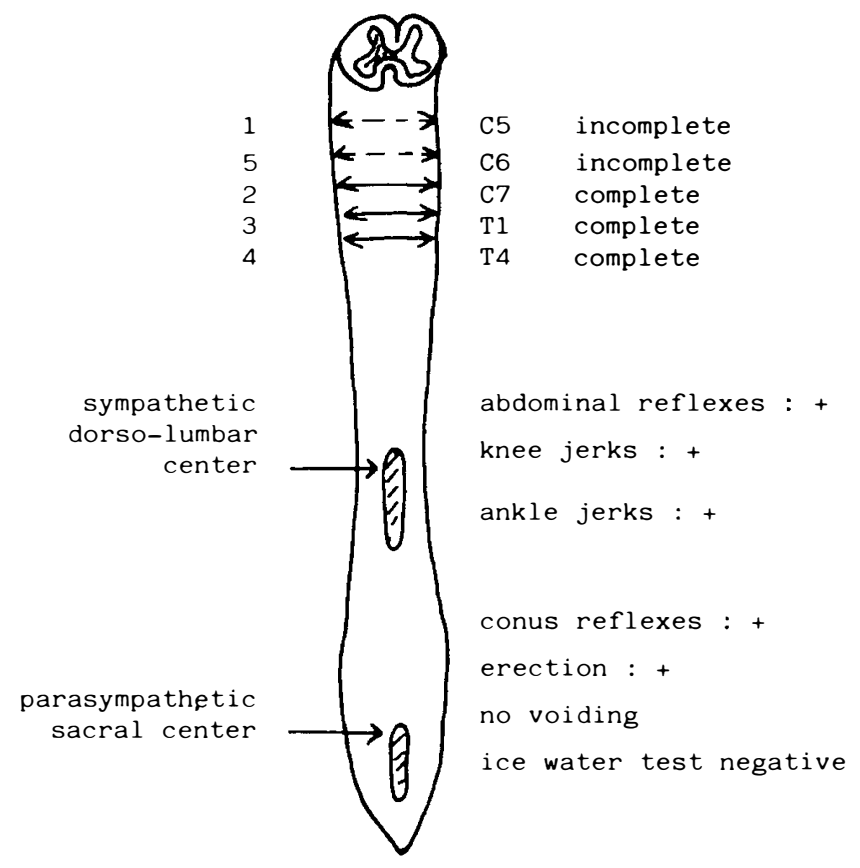

Figure 1. Clinical data in five spinal cord injured male patients out of spinal shock. Note that the sympathetic dorsolumbar and the parasympathetic sacral centres are widely under the spinal cord lesion. The five patients have the same sub-lesional reflex activity (abdominal, lower limbs, conus reflexes) according to the schema.

any sign of clinical activity, there was no voiding. An intermittent catheterisation programme, carried out every three hours, was maintained. Urine volume between two catheterisations never exceeded $500 \mathrm{ml}$. Bladder inactivity was supposedly caused by a lack of detrusor reflex activity since attempts to induce micturition reflexes as well as an ice-water test were negative. In spite of the incompleteness of his lesion the fifth patient could only void with the help of a strong Credé manoeuvre. Both micturition reflexes and the ice-water test were negative.

Urodynamic studies were performed in all five patients with simultaneous vesical and rectal pressure and anal E.M.G. recordings. Both low compliance and detrusor areflexia were observed even with high bladder volumes. Urecholine tests $(2,5 \mathrm{mg}$ bethanechol chloride subcutaneously) were always negative. Urethral pressure profiles (except in patient number 3 because of technical reasons) with a catheter withdrawal speed of $10 \mathrm{~cm} / \mathrm{min}$ displayed high values, always above $150 \mathrm{~cm} \mathrm{H}_{2} \mathrm{O}$. Bilateral pudendal blocks (Xylocaine $10 \mathrm{ml}, 1 \%$ ) caused a transient decrease in the maximal urethral pressure (M.U.P.) but did not modify the bladder activity or the voiding pattern. The same results were obtained in a patient from a series of six peri-striated urethral muscle infiltrations with xylocaine $(10 \mathrm{ml}, 1 \%)$, (Grondard et al., 1978). Oral antispastic agents such as Baclofen $60 \mathrm{mg} /$ day + Diazepam $20 \mathrm{mg} /$ day or Dantrolene $350 \mathrm{mg} /$ day failed to influence detrusor activity. Intravenous pyelography and retrograde urethrography were always normal. 
In three patients urodynamic recordings were carried out before and after one or two days following the intravenous administration of $15 \mathrm{mg}$ P.O.B. Two other patients who received $40 \mathrm{mg}$ P.O.B. per os daily for 15 days had urodynamic recordings carried out before and after completion of treatment.

\section{Results}

Following the intravenous injection of P.O.B., M.U.P. decreased immediately by about 40 per cent without any concomitant change in detrusor activity. However, 12 to 36 hours later voiding episodes did occur. Cystometric examination showed that micturition correlated with the appearance of detrusor activity. M.U.P. remained essentially normal (Fig. 2). The oral administration of P.O.B. gave similar results (Table 1). Five patients were treated with oral P.O.B. (40 mg daily) from 2 weeks to 1 year. Although only three of them retained a balanced bladder function, all showed detrusor activity on cystometric recordings after cessation of the treatment for 8 days. These observations lead us to believe that after some time alpha-blocking agents are no longer necessary.

\section{Discussion}

Five patients have been reported who presented with a high spinal cord injury level, absence of detrusor activity after spinal shock, a negative urecholine test

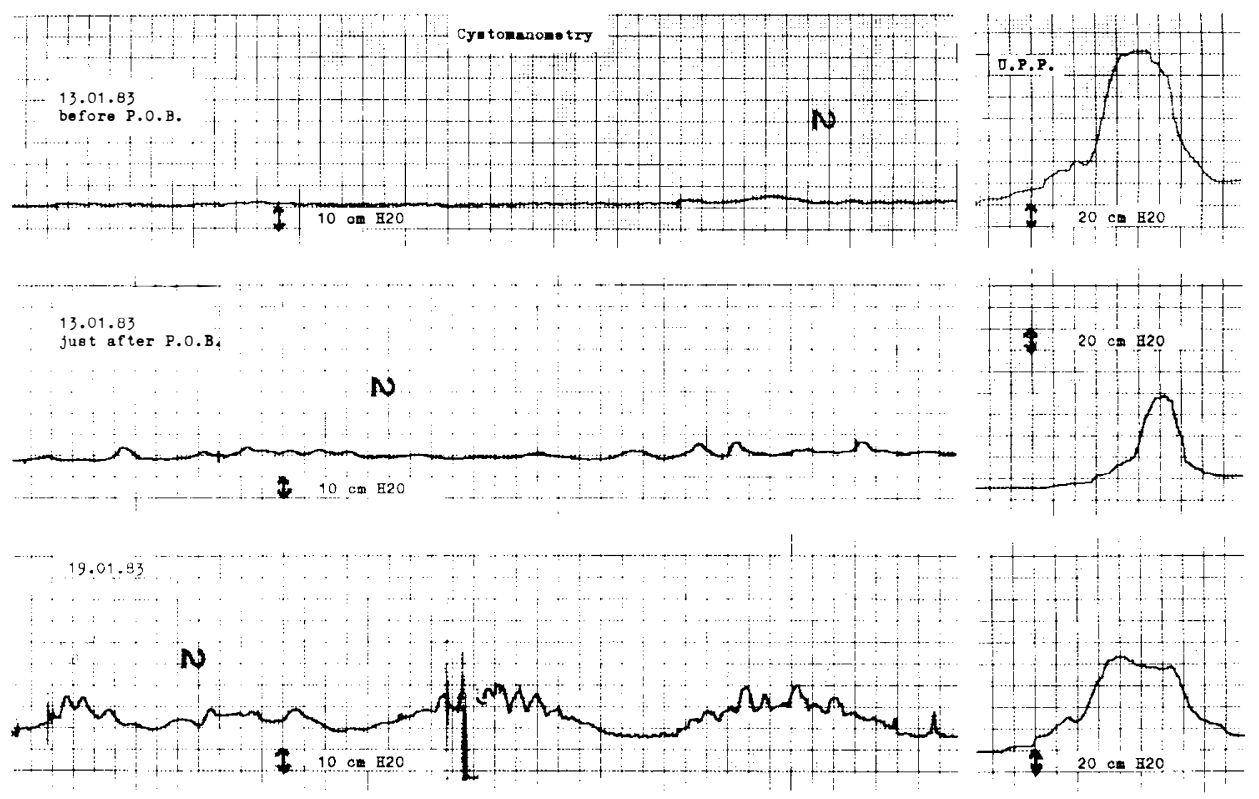

Figure 2. Case 1. Urodynamic recording (4 months postInjury) before (upper), just after (middle), and six days after (below) intravenous P.O.B.

Before the test there is a lack of detrusor activity and a high M.U.P. P.O.B. injection induces a decrease of urethral pressure but no change of detrusor activity. Another recording six days later still shows a decreased M.U.P. but also detrusor activity. (patient started to void). 
Table 1 Urodynamic data in five patients before and after phenoxybenzamine administration. Note that detrusor activity appeared with some delay after the test

\begin{tabular}{cccccccc}
\hline Patients & DA & MUP & $\begin{array}{c}\text { P.O.B. } \\
\text { Test }\end{array}$ & DA & MUP & DA & MUP \\
\hline 1 & - & 110 & $-\mathrm{IV} \rightarrow$ & - & 80 & + & 80 \\
4 & - & 160 & $-\mathrm{IV} \rightarrow$ & - & 80 & + & 80 \\
5 & - & 180 & $-\mathrm{IV} \rightarrow$ & - & 110 & + & 100 \\
& & & & & & + & 100 \\
2 & - & 160 & - per os- & NA & -per os & Just after test & $\begin{array}{c}+ \\
12-48 \text { h after test }\end{array}$ \\
\hline
\end{tabular}

D.A.: Detrusor activity (cystometric data).

M.U.P.: Maximum urethral pressure $\left(\mathrm{cm} \mathrm{H}_{2} \mathrm{O}\right)$.

P.O.B. Test: Phenoxybenzamine test $(I V: 15 \mathrm{ml}$, in patients $1,4,5$,

N.A.: not applicable.

PER OS: $40 \mathrm{mg} /$ day, in patients 2,3 )

$-:$ no activity.

+ : contraction wave.

and a high M.U.P. In those cases, however, P.O.B. induced micturition and cystometric appearance of bladder activity 12 hours after intravenous P.O.B. injection.

After spinal shock some patients with suprasacral spinal cord lesions will show detrusor inactivity with retention. There may be several explanations for this condition.

Bladder overdistention with secondary detrusor hypotonia could be excluded in our patients because all were catheterised every 3 hours. As a rule reflex detrusor activity returns within 1 to 2 months after bladder drainage by indwelling catheter or intermittent catheterisation (Willot and Maury, 1981). It follows that bladder overdistention could not be retained as an hypothesis to explain prolonged bladder inactivity and areflexia over several months or years after spinal shock.

A concomitant lower motor neuron lesion could be excluded as shown by the presence of conus reflexes, reflex erections, and a negative denervation supersensitivity test with Urecholine.

Although without definite explanation (Yalla et al., 1977), detrusor inactivity of central origin described by some authors could be hypothesided, or sphincter dyssynergia with detrusor areflexia (Andersen and Bradley, 1976). It should be remembered that there are reciprocal influences between sympathetic, parasympathetic, and somatic systems coordinating the sphincter-detrusor function (Buzelin, 1981; McGuire et al., 1979).

Inhibition of the parasympathetic centre by the sacral somatic neurons has been demonstrated in paraplegics. According to McGuire et al. (1979), it is part of the sphincter-detrusor dyssynergia, as the activity of the striated sphincter increases with bladder filling with poor detrusor responses. The detrusor inhibitory reflex from the somatic system is a physiological mechanism in man.

If parasympathetic inhibition from the somatic system is suspected, striated activity should be reduced by pudendal nerves blocks, parastriated infiltrations and/or antispastic medications. However, in our patients, such an inhibitory reflex could not be suppressed in this way. 
If the role of an alpha-blocking activity on the sacral parasympathetic centre is considered to explain detrusor inactivity in our cases, two main facts should be stated. First, high M.U.P. consistently decrease following the administration of alpha-blocking agents (Rossier et al., 1982). Second, alpha-blocking agents induce detrusor activity without any relationship with the M.U.P. decrease. That decrease which was also obtained by pudendal blocks failed to influence detrusor activity.

How do alpha-blocking agents act on the detrusor? A direct activity on detrusor alpha-receptors is unlikely. On the one hand acetylcholine receptors are predominant and there are but a few alpha-receptors, on the other hand, the effect of the medication is delayed in contrast to what happens to the M.U.P.

It is proposed that alpha-blocking agents act on the parasympathetic inhibitory reflex mediated by the sympathetic system (Nergardh and Kinn, 1983). In the cat De Groat and Saum (1972) have shown that stimulating the sympathetic system inhibits the parasympathetic centre. Anatomical interconnections have been disclosed in animal between sympathetic and parasympathetic systems in the pathways from the lumbo-sacral centres to the bladder and particularly in the ganglionic perivesical plexus (Schulman et al., 1972). The micturition parasympathetic centre could be under continuous inhibitory control from sympathetic origin as would be the case in patients with spinal cord lesions above the thoracolumbar sympathetic centre (McGurie et al., 1976).

Our results suggest that the inhibition of the sacral parasympathetic centre is under sympathetic predominance which can be decreased by alpha-blocking agents. At that time it is not possible to determine their level of action. As detrusor activity persists after discontinuation of P.O.B., it may be that this drug acts as a triggering agent in establishing a voiding pattern.

Our results with alpha-blocking agents on the bladder activity point to an obvious difference compared to those of a previous study where alpha-blocking agents were shown to be also capable of inhibiting bladder activity in patients with upper motor neuron lesion (Rossier et al., 1983). In fact, there are two phenomena which are quite different. One one hand, in our cases, P.O.B. allows bladder activity to occur (from previous inactivity), on the other hand, P.O.B. only diminishes the pattern of uninhibited bladder contractions. These are not two opposite conditions but rather two different ones.

To sum up, in upper motor neuron lesions bladder inactivity can be found in two different situations, i.e., during and after spinal shock. During spinal shock urodynamic findings show absence of detrusor contractions and a marked alpha-sympathetic activity in the urethra (Rossier et al., 1980). In these cases, P.O.B. reduces the M.U.P. but never induces bladder activity. On the other hand in some cases after spinal shock detrusor inactivity could be due to sympathetic overactivity and reversed by alpha-blocking agents.

\section{Résumé}

Les auteurs rapportent cinq observations d'inactivité paradoxale du détrusor dans des lésions médullaires cervicales ou dorsales hautes avec spasticité sous-lésionnelle, notamment au niveau du périnée. Dans tous ces cas, l'administration d'un alpha-bloquant (Phenoxybenzamine) fit apparaître une activité vésicale. Les auteurs discutent la possibilité d'une inhibition réflexe du centre parasympathique sacré à point de départ sympathique, réversible par la Phenoxybenzamine. 


\section{Zusammenfassung}

Die Verfasser berichten über fünf Patienten mit zervikalen und hoch gelegenen dorsalen Querschnittsläsionen, die trotz infraläsionärer Spastizität, besonders des Beckenbodens, eine paradoxe Detrusorinaktivität zeigten.

In jedem Fall ließ die Verabreichung eines alpha-Blockers eine Tätigkeit der Blase erscheinen.

Es ist vorgeschlagen, dass es eine reflektonische von dem sympathischen System herausstemmende Hemmung über das sakrale parasympathische Zentrum gibt, die durch Phenoxybenzamin unwendbar ist.

\section{References}

ANDERSEN JT, BRADLEY WE 1976 The syndrome of detrusor sphincter dyssynergia. Journal of Urology 116:493-495

BrUZELIN JM 1981 La pathologie de l'inhibition vésicale. I. L'organisation neurologique de la fonction vésico-sphinctérienne. Journal D'Urologie et de Nephrologie 87:479-506

De Groat WC, SAUM WR 1972 Sympathetic inhibition of the urinary bladder and of pelvic ganglionic transmission in the cat. Journal of Physiology 220:297-314

Grondard E, Francois N, MaUry M, Cukier J 1978 Les infiltrations para-sphinctériennes anesthésiques du sphincter strié de l'urètre chez le paraplégique. Résultats sur 83 cas. Journal D'Urologie et de Nephrologie 84:207-214

Labat JJ, Le Coguic G, Mathe JF, Buzelin JM 1982 Inactivité du détrusor dans les lésions médullaires centrales. Journal D’Urologie et de Nephrologie 88:527-530

MCGuire EJ, WAGNer FM, Weiss RM 1976 Treatment of autonomic dysreflexia with phenoxybenzamine. Journal of Urology 115:53-55

MCGuire EJ, BRAdy S 1979 Detrusor sphincter dyssynergia. Journal of Urology 121:774-777

NeRGARDH A, KINN ACH 1983 Neurotransmission in activation of the contractile response in the human urinary bladder. Scandinavian Journal of Urology and Nephrology 17:153-157

Rossier AB, Fam BA, Dibenedetto M, Sarkarati M 1980 Urethro-vesical function during spinal shock. Urological Research 8:53-65

Rossier AB, Fam BA, Lee IY, Sarkarati M, Evans DA 1982 Role of striated and smooth muscle components in the urethral pressure profile in traumatic neurogenic bladders: a neuropharmacological and urodynamic study. Preliminary report. Journal of Urology 128:529-535

Rossier AB, Fam BA, Lee IY, Sarkarati M, Evans DA 1983 The respective contribution of smooth and striated components in the urethral pressure profile in the spinal cord injured. A neuropharmacolological and urodynamic study. Paraplegia 21:114-116

Schulman CC, Duarte-Escalante O, Boyarsky S 1972 The ureterovesical innervation. A new concept based on a histochemical study. British Journal of Urology 44:698-712

Willot JP, MAURY M 1981 Le passage du drainage à l'autonomie. In: M. Maury (ed) La Paraplégie, pp. 253-259, Flammarion Médecine-Sciences: Paris.

Yalla SV, Blunt KJ, Fam BA, Constantinople NL, Gittes RF 1977 Detrusor urethral sphincter dyssynergia. Journal of Urology 118:1026-1029 